\title{
Undergraduates' Academic Performance, Self-Esteem and Perceived Social Support as Determinants of Perceived Stress
}

\author{
Kenny Lau Wee Keat \\ Faculty of Business, Economics and Accounting and Economic \\ HELP University, 50490 Kuala Lumpur, Malaysia \\ E-mail: Kenny_3411@hotmail.com \\ Wong Siew Chin (corresponding author) \\ Faculty of Business, Economics and Accounting and Economic \\ HELP University, 50490 Kuala Lumpur, Malaysia \\ E-mail: sc.wong@ @elp.edu.my
}

\section{Lim Chui Seong}

Faculty of Business, Economics and Accounting and Economic

HELP University, 50490 Kuala Lumpur, Malaysia

E-mail: chuiseong.lim@help.edu.my

Received: Sep. 19, 2018 Accepted: Oct. 12, 2018 Online published: Oct. 23, 2018

doi:10.5296/ijhrs.v8i4.13668

URL: https://doi.org/10.5296/ijhrs.v8i4.13668

\begin{abstract}
The aim of current paper is to investigate the relationships between academic performance, self-esteem, perceived social support and perceived stress among the undergraduates in both Malaysian public and private universities. Research data is gathered from a sample of 144 of undergraduates from public and private universities in Malaysia. Partial Least Squares Structural Equation Modelling (PLS-SEM) is employed to examine the influences of academic performance, self-esteem, perceived social support and perceived stress among the undergraduates. The results demonstrate that self-esteem and perceived social support are
\end{abstract}


viewed as potential predictors of perceived stress among undergraduates. However, there is no significant relationship between academic performance and perceived stress. Future researchers are suggested to conduct similar researches in qualitative or experimental setting in order to minimize personal bias in a longitudinal design. Current paper provides new in-depth and practical implications to all parties to pay attention in efforts to improve undergraduate's well-being and achievement in their tertiary education stage. This paper offers new insight into the predicting factors of perceived stress among undergraduates in Malaysian context.

Keywords: perceived stress, academic performance, self-esteem, perceived social support

\section{Introduction}

Most of us are aware that stress is an increasing issue either in individual's life or organization. Stress is indicated as a significant aspect of survival techniques. It assists individual to interpret the situations well so one could apply the mechanism of "fight-or-flight" (Adamo, 2012). Being as a double-edged sword, excessive stress could harm a person physically and psychologically such as suicidal behaviour, depression, post-traumatic stress disorder (PTSD) and self-mutilation (Zhang and Li, 2013). Furr, Westefeld, McConnell and Jenkins (2001) reported that students experienced depression problem due to academic-related factors. They have thoughts in committing suicide since coming to colleges/universities. Malaysian statistical data showed that the increasing of suicide rate from originally 5.3 percent increased to 5.5 percent in year 2005 to 2016 (WHO, 2017). The stressors associated with study loads, pressure to complete required tasks, and time urgency are hindrance stressors that keep individuals from reaching the goals. Malaysia local authorities are urged to take immediate countermeasures to improve mental health development program urgently as 4.2 million of youths who were aged 16 and above were suffering from different types of mental illness (Yunus, 2018).

Previous studies have consistently found the correlations between individual-related factor and perceived stress (Opoku-Acheampong, Kretchy, Acheampong, Afrane, Ashong, Tamakloe and Nyarko, 2017; Anuradha, Dutta, Raja, Sivaprakasam and Patil, 2017). Most studies on perceived stress level have been centred in the west (Negga, Applewhite and Livingston, 2007; Mihăilescu, Diaconescu, Donisan and Ciobanu, 2016; Opoku-Acheampong et al., 2017), and there is lacking of empirical evidence is found in Malaysia, particularly undergraduates group. Thus, current study aimed to find out the relationships between academic achievement, self-esteem, perceived social support and perceived stress among both private and public universities undergraduates. The study would provide useful insights to local higher education institutions authorities in order develop the values-driven, competent and high self-efficacy undergraduates as outlined in Malaysia Education Blueprint 2013-2025 (Ministry of Education Malaysia, 2013), and Malaysian Economic Transformation Programme (Prime Minister's Department, 2011).

This paper is organized as follows: We begin by reviewing the definition of perceived stress, followed by presenting related empirical studies on the association between independent variables and perceived stress. The next section describes the methodological aspect of this 
research, followed by the research findings and discussion. We conclude the paper by outlining the implications of the study for research and management practices as well as the limitations and directions for future studies.

\section{Literature Review}

\subsection{Perceived Stress}

A model of stress explains why and how individuals experience stress based on several potential sources (Robbins and Judge, 2013). According to the model, stress is associated with environmental, organizational and personal factors as well as individual differences. In this context, task demands, role demands and interpersonal demands are critical to affect the stress level among undergraduates. For instance, academic performances is viewed as task and role demand of which explains the expectation and requirements of academic performances could generate individual's perceived stress level (Robbins and Judge, 2013). Yan, Lin and Su (2018) explained that when one is facing a high demand where there is a lack of resources, it could cause a stressful experience for individual. Meanwhile, self-esteem was considered as perception of individual differences which generate stress for individual. Some people may have inherent tendency to accentuate negative aspects of world which would become a significant individual factors that influence stress as a person's basic disposition. (Robbins and Judge, 2013). Similarly, interpersonal demands are pressures created by others. Lack of social support from peers and poor interpersonal relationship can cause stress among individuals.

According to Brown, Anderson-Johnson and McPherson (2016), undergraduates always perceive the education as a highly stressful process which required high demand of physical and mental readiness and involvement. The negative symptoms such as poor sleep quality, poor appetite, emotional distress, acute stress and depression are experienced by undergraduates. They revealed that the main reasons of stress are related to poor academic achievement, poor cognitive functioning and poor attentiveness and mindfulness (Brown et al., 2016). Stress could also leads to suicidal case due to suffering of overstressing and burnout emotion from achieving academic expectation. Yan et al. (2018) stressed that individual experiences high level of stress when he/ she is facing a high demand for academic expectations/outcomes and there is a lack of resources to accomplish such outcomes. In this context, there were cases that Malaysian undergraduates committed suicide due to pressure of study and lack of appropriate stress management interventions provided by the relevant parties (The Star Online, 2013).

\subsection{Academic Performance}

According to Mihăilescu et al. (2016), academic performances are achievements in education such as performance of enrolled subjects, class participation and even the small quizzes in class. Based on tertiary education requirement, failing courses are considered as an academic failure which delays the academic completion (Guerra-Martín, Lima-Serrano and Lima-Rodríguez, 2017). The undergraduates are required to re-sit/retake the relevant subjects accordingly. They might perceive themselves as having low resources to retake the subjects 
such as time, money and motivation according to the theory of learnt helplessness (Ciccarelli and White, 2015). Hence, the students are more likely to have high perceived stress due to poor academic performances (Ganguly, Kulkarni and Gupta, 2017; Jenaabadi, Nastiezaie and Safarzaie, 2017).

Based on Carl Rogers's Person-Centered Theory (Telles, Boris and Moreira, 2014), actualizing tendencies are one of the processes that individual go through in order to produce a result of congruent or harmony. Noteworthy to explain that the concept of incongruence would affect most of the people who are experiencing depression and anxiety as their real self (eg. academic failure) and ideal self (eg. academic achiever) are not close to each other (Ciccarelli and White, 2015). As a result of incongruence, one might experience stressful life as he or she is unable to handle the sense of unworthiness. They feel depress and stressful when they failed to achieve the ideal self as part of the vision of their own life particularly in their tertiary study lives. According to Ganguly et al.'s empirical study (2017) on 372 freshmen and 232 senior undergraduates, they revealed that there was significant negative relationship between academic performance and academic stress. It indicated that students who have poor academic achievement were expected to experience high level of stress.

\subsection{Self-Esteem}

Self-esteem is defined as an individual's perception on his own regardless of positive view or negative view (Ciccarelli and White, 2015). It indicates on how one could rate himself based on self-worthiness ( $\mathrm{Ju}$ and Lee, 2018). Individual will experience different stress level due to different perception on personal's strengths. Previous literatures indicated that high level of stress was correlated to low self-esteem among the nursing and pharmacy students (Mimura, Murrells and Griffiths, 2009). The findings emphasized that individual with low self-esteem are both high in external locus of control and learnt helplessness, and contributing to higher stress level (Ciccarelli and White, 2015).

According to Ferradás Canedo, Freire Rodríguez, Regueiro Fernández and Valle Arias (2018), they revealed that the students who had higher self-esteem reported that low level of defensive pessimism. Meszaros and De Wals (2011) added that individual with low self-esteem would have a higher sensitivity on how others perceive them. This often leads them to be protective by hiding personal emotions, facial expressions, and avoiding interactions with the others. These negative responses affect their socialization activities and leads to high stress level in life. The individual's self-esteem will be eroded gradually when there is increasing levels of stress.

\subsection{Perceived Social Support}

According to Adisa, Olajide and Fakeye (2017), perceived social support is a perception on help and assistance received from surrounding people such as peers, friends and family members. There are three types of social support namely psychological support, instrumental support and informational support (Yurdakul, 2018). Psychological/emotional support is sourced from understanding sympathizing and empathizing; instrumental/physical support is referring to material needs such as financial support; informational support is known as 


\section{Al Macrothink}

International Journal of Human Resource Studies

ISSN 2162-3058 2018, Vol. 8, No. 4

providing information and data as a resources for problem solving.

Cognitive Appraisal and Stress model (Lazarus, 2000) was employed to explain the relationship between perceived social support and perceived stress. The model explains that an individual could experience high level of stress when he or she is facing the life challenges. Under such circumstances, individuals would make two types of appraisal which are primary appraisal and secondary appraisal. Based on primary appraisal, the individuals would ask themselves that "Is the issue going to be a threat?" After perceiving the threat, they will proceed to the second appraisal stage in order to identify and understand how much resources is available to counter the problems. Throughout these two appraisal process, stress level will be determined as high or low level (Lazarus, 2000). Çivitçi and Durmuş's study (2015) on 479 undergraduates in Turkey revealed that there was a significant negative relationship between perceived social support and perceived stress. The experiences of peer rejection and poor socialization can lead to higher level of stress among undergraduates (Wainer, 2013, Fernández-González, González-Hernández and Trianes-Torres, 2015)

Thus, the hypotheses in current study is as follows:

H1: There is a significant negative relationship between academic performance and perceived stress among Malaysian undergraduates.

H2: There is a significant negative relationship between self-esteem and perceived stress among Malaysian undergraduates.

H3: There is a significant negative relationship between perceived social support and perceived stress among Malaysian undergraduates.

\section{Research framework}

Based on reviews of related literature, we proposed a research framework of perceived stress among undergraduates. Figure 1 depicts the research framework and the hypothesized relationships in the study.

$\underline{\text { Independent Variables }} \quad \underline{\text { Dependent Variable }}$

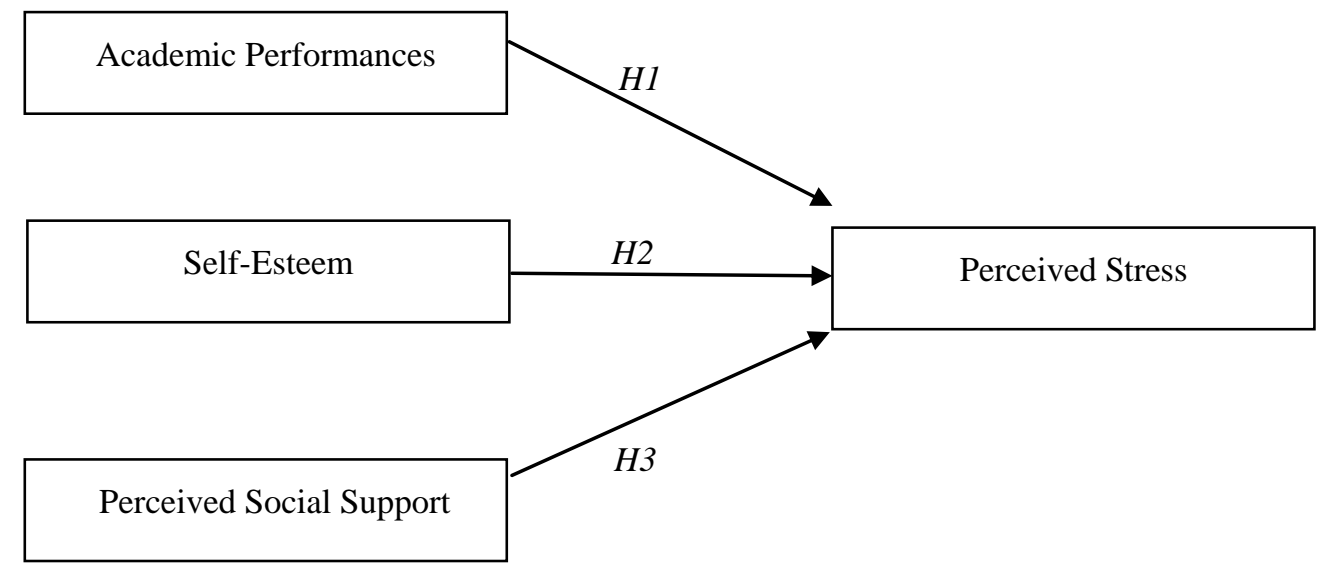

Figure 1. Research Framework 


\section{Methodology}

\subsection{Population and Sample}

The quantitative research was conducted in both Malaysian public and private universities. The cross-sectional design was used to determine the relationship between academic performance, self-esteem, perceived social support and perceived stress among Malaysia undergraduates. Non-probability sampling method was adopted for current research (Swacha, Botta-Dukát, Kącki, Pruchniewicz and Żołnierz, 2017). Convenience and snowball sampling were used to reach the potential respondents who are undergraduates pursuing tertiary education in Malaysia private and public universities currently.

A total of 144 respondents were involved in the survey. Based on snowball sampling method, this study involved $31 \%$ male and $69 \%$ female undergraduate students. $57 \%$ of the respondents are from public universities. $43 \%$ of respondents are from private universities. The respondents were from different faculties such as business, science, medical, law, education and others. About $33.3 \%$ of respondents were from business or behavioral science faculty, $29.2 \%$ from engineering/ medical/ science faculty, $18.9 \%$ from education faculty and 18.9 from others. In addition, the respondents consisted of year 1 (19.8\%), year $2(45.2 \%)$ and year $3(35.0 \%)$ undergraduates. Lastly, the CGPA of the respondents range below 2.50 was $5.6 \%$, the range of 2.5 to $3.24 ; 3.25$ to 3.74 and 3.75 to 4.0 were $21.4 \%, 52.8 \%$ and $20.2 \%$ respectively.

Partial Least Squares Structural Equation Modeling (PLS-SEM), SmartPLS 3.0 version was used to test the hypotheses. According to Hair, Hult, Ringle and Sarstedt (2017), PLS-SEM was adopted as statistical means for testing structural equation models is as follows: (i) PLS makes fewer demands regarding sample size than other methods, (ii) PLS does not require normal-distributed input data, (iii) PLS is better suited for theory development especially useful for prediction. The next section presents the assessment of the goodness of measure of the constructs in terms of their validity and reliability.

\subsection{Research Instruments}

\subsubsection{Perceived Stress}

The construct was measured by using Perceived Stress Scale (PSS) (Cohen,1994), which consisted of 8 items with a five-point Likert scale such as 1 'Never'; 2 'Almost Never'; 3 'Sometimes'; 4 'Fairly Often'; 5 'Very Often'. Sample items was "In the last month, how often have you been upset because of something that happened unexpectedly?". The composite reliability was 0.93 in this study.

\subsubsection{Academic Performance}

The academic performance questionnaire (5-point Likert scale) was adapted and adopted from Tangaraju, Ho, Tan, Tan and Tan's study (2013). The 5 items of five-point Likert scale from the ranging of 1 'Strongly Disagree' to 5 'Strongly Agree' was employed in measurement items. Sample questions was "I perform poorly in my past semester examinations.". The composite reliability was a total of 0.83 . 


\subsubsection{Self-esteem}

This construct was measured by using Rosenberg Self-Esteem Scale. It is consisted of 10 items and measured in 5 point Likert scale with values $1=$ "strongly disagree" to $5=$ " strongly agree" The sample item was "On the whole, I am satisfied with myself.". The composite reliability was 0.87 .

\subsubsection{Perceived Social Support}

The Multidimensional Scale of Perceived Social Support was used to measure this construct. The dimensions including individual's perception on how much support he received from family (Fam), friends (Fri) and significant other (SO). The 12 items were measured in five points Likert scale which were ranging from 1 'Strongly Disagree' to 5 'Strongly Agree'. Sample item was "There is a special person who is around when I am in need." The composite reliability in the analysis was 0.92 .

\subsection{Convergent Validity}

We tested the convergent validity which is the degree to which a set of indicators (items) that presume to measure a construct fit the theories (Hair et al., 2017). It represents the strength of the relationships between items that are predicted to represent a single latent construct. Based on Hair et al. (2017), factor loadings, composite reliability and average variance extracted (AVE) (i.e., the sum of the squared loadings divided by the number of indicators) were used to examine convergent validity. As showed in Table 1, the loadings for all items were greater than the recommended value of .5 (Hair et al., 2010). The factor loadings which less than 0.7 such as PS4 and PS6 (perceived stress); AP1 and AP2 (academic performance); SE3, SE4, SE5, SE7 and SE8 (self-esteem) and PSS3, PSS4, PSS8, PSS11, PSS5 and PSS10 (perceived social support) were removed in order to improve the AVE score. Composite reliability indicated the latent constructs ranged from .87 to .93 which exceeded the recommended value of 7 (Hair et al., 2010). Subsequently, the AVE (to measure the variance captured by the indicators relative to measurement error) for respective constructs were above the recommended value of .5 (Hair et al., 2010). Thus, convergent validity requirement was fulfilled in this study.

\subsection{Discriminant Validity}

On the other hand, discriminant validity was assisting the researcher to determine whether the particular construct was accurately different with other constructs in terms of empirical standards and distinct definition (Hair et al. ,2017). The discriminant validity can be accessed vigorously that the correlations for each construct were less than the square root of AVE for the indicators measuring that particular construct, which indicating adequate discriminant validity. In total, Table 2 indicated the measurement model demonstrates adequate convergent and discriminant validity in this study 
Table 1. Result of measurement model

\begin{tabular}{lcccc}
\hline \multicolumn{1}{c}{ Construct } & Item & Loading & AVE & CR \\
\hline Academic Performance & AP3 & 0.787 & 0.636 & 0.839 \\
Perceived Stress & AP4 & 0.711 & & \\
& AP5 & 0.884 & & 0.931 \\
PS1 & 0.861 & 0.692 & \\
PS2 & 0.837 & & \\
PS3 & 0.827 & & \\
Self-Esteem & PS5 & 0.765 & & \\
& PS7 & 0.842 & & \\
PS8 & 0.854 & & \\
Perceived Social Support & SE1 & 0.738 & 0.591 & \\
& SE2 & 0.746 & & \\
& SE6 & 0.843 & & \\
& SE9 & 0.702 & & \\
& SE10 & 0.808 & & \\
& PSS6 & 0.891 & 0.758 & \\
& PSS7 & 0.896 & & \\
& PSS9 & 0.841 & & \\
& PSS12 & 0.854 & & \\
\hline
\end{tabular}

Table 2. Discriminant Validity

\begin{tabular}{ccccc}
\hline & $\begin{array}{c}\text { Academic } \\
\text { Performance }\end{array}$ & $\begin{array}{c}\text { Perceived Social } \\
\text { Support }\end{array}$ & $\begin{array}{c}\text { Perceived } \\
\text { Stress }\end{array}$ & Self-esteem \\
\hline $\begin{array}{c}\text { Academic } \\
\text { Performance } \\
\text { Perceived }\end{array}$ & $\mathbf{0 . 7 9 7}$ & & & \\
Social Support & 0.169 & $\mathbf{0 . 8 7 1}$ & & \\
Perceived & -0.272 & -0.382 & $\mathbf{0 . 8 3 2}$ & \\
Stress & & & & \\
Self-esteem & 0.375 & 0.429 & -0.574 & $\mathbf{0 . 7 6 9}$ \\
\hline
\end{tabular}

Note: Diagonals represent the square root of the AVE while the off-diagonals represent the correlations

Based on the results of PLS-SEM algorithm, all of the items in the measurement models were having the collinearity statistics (VIF) values which were higher than 0.20 but lower than 5.0 as the conservative threshold of assessment of collinearity among the constructs in the structural model (Hair et al. 2017), except PSS1 and PSS2 which were exceeding the acceptable VIF values of 5 such as 5.130 and 6.133, respectively. In other words, these two items would cause lateral and vertical collinearity among constructs. Hence, PSS1 and PSS2 were deleted before proceeding to bootstrapping calculation. The model is free from 


\section{Macrothink}

pathological collinearity.

Table 3 and Figure 2 present the results of the postulated hypotheses. The $\mathrm{R}^{2}$ value indicated that $35.6 \%$ of the variance in the perceived stress is explained by self-esteem and perceived social support. Further analysis shows that self-esteem $(\beta=-0.479, p<.01)$, and perceived social support $(\beta=-0.166, p<.05)$ were negatively related to perceived stress. Thus, $\mathrm{H} 2$, and $\mathrm{H} 3$ were supported. A close examination explained that self-esteem was more important as compared with perceived social support. However, there is no significant negative relationship between academic performance and perceived stress $(\beta=-0.064, \mathrm{p}>0.05), \mathrm{H} 1$ was rejected.

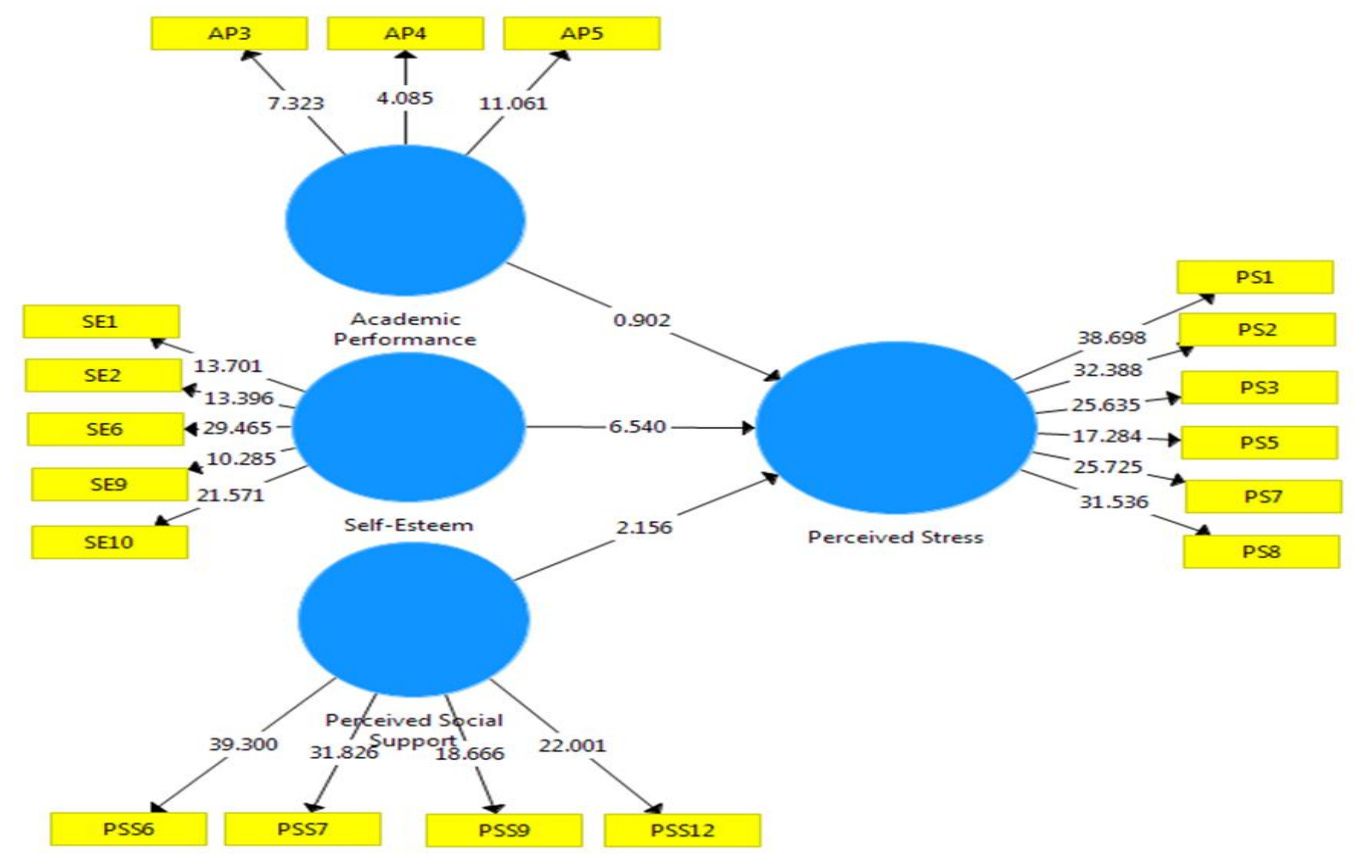

Figure 2. Result of Path Analysis (Structural Model)

Table 3. Summary of the structural model

\begin{tabular}{lcccccc}
\hline & $\begin{array}{c}\text { Path } \\
\text { Coefficient }\end{array}$ & SE & T-value & P-value & Decision \\
\hline $\begin{array}{l}\text { Academic Performance } \rightarrow \\
\text { Stress (H1) }\end{array}$ & Perceived & -0.064 & 0.071 & 0.902 & 0.184 & Not Supported \\
Self-Esteem $\rightarrow$ Perceived Stress (H2) & -0.479 & 0.072 & 6.540 & $0.000^{* * *}$ & Supported \\
& & & & & \\
$\begin{array}{l}\text { Perceived Social Support } \rightarrow \text { Perceived } \\
\text { Stress (H3) }\end{array}$ & -0.166 & 0.075 & 2.156 & $0.014^{* * *}$ & Supported \\
\hline
\end{tabular}

$* * \mathrm{p}<0.05 ; * * * \mathrm{p}<0.01$

The $\mathrm{f}^{2}$ effect size is commonly used to determine the impacts of an independent variable to 
the dependent variable's $\mathrm{R}^{2}$ value (Hair et al., 2017). Table 4 indicated that there is no effect of academic performance on perceived stress $\left(\mathrm{f}^{2}=0.005\right)$, small effect size for perceived social support $\left(\mathrm{f}^{2}=0.035\right)$ and medium effect size for self-esteem $\left(\mathrm{f}^{2}=0.257\right)$. $\mathrm{Q}^{2}$, which is known as predictive relevance is to predict the indicators in terms of reflective measurement models of dependent variables (Hair et al., 2017). Predictive Relevance, $Q^{2}$, which is 0.223 larger than 0 interpret that exogenous constructs are having the ability of predictive relevance on endogenous construct (Table 5) (Hair et al., 2017).

The $\mathrm{q}^{2}$ effect size determines the contribution of the independent variables to a dependent variable's $\mathrm{Q}^{2}$ value. The rules of thumb are basically identical with the standard of $\mathrm{f}^{2}$ effect size which are $.02, .15$ and .35 where they indicate a small, medium and large predictive relevance for the dependent variables (Hair et al., 2017). Based on Table 4, the effect size of predictive relevant $\left(\mathrm{q}^{2}\right)$ for self-esteem and perceived social support were medium $\left(\mathrm{q}^{2}=0.119\right)$ and small $\left(q^{2}=0.02\right)$ respectively. However, there is insignificant predictive relevant effect size for academic performance $\left(q^{2}=0.002\right)$ (Hair et al., 2017).

Table 4. Summary of the structural model

\begin{tabular}{cccc}
\hline Hypothesis & Relationship & $f^{2}$ & $q^{2}$ \\
\hline $\mathrm{H}_{1}$ & Academic Performance--> Perceived Stress & 0.005 & 0.002 \\
$\mathrm{H}_{2}$ & Self-Esteem --> Perceived Stress & 0.257 & 0.119 \\
$\mathrm{H}_{3}$ & Perceived Social Support --> Perceived Stress & 0.035 & 0.020 \\
\hline
\end{tabular}

Table 5. Summary of Predictive Relevance $\left(Q^{2}\right)$

\begin{tabular}{lccc}
\hline & SSO & SSE & $\mathrm{Q}^{2}(=1-\mathrm{SSE} / \mathrm{SSO})$ \\
\hline Academic Performance & 432.000 & 432.000 & 0.223 \\
Perceived Social Support & 576.000 & 576.000 & \\
Perceived Stress & 864.000 & 671.719 \\
Self-Esteem & 720.000 & 720.000 \\
\hline
\end{tabular}

\section{Discussion}

Present study found that there was no significant negative relationship between academic performances and perceived stress $\left(\mathrm{H}_{1}\right)$. The current finding was consistent with the findings of Hasan and Fatima (2017). Due to the challenges of competitive global business environments, massive restructuring and downsizing have been implemented by many organizations in order to enhance organizational efficiency and flexibility. Inevitably, many employers focus on the distinctive capabilities (i.e., soft skills) of the employees in order to support the business strategies implementation (Ali and Mahmod, 2018; Brill, Gilfoil and Doll, 2014). Nowadays, many undergraduates (i.e., generation Y) started to change their 
awareness in order to focus on appropriate attitudes and soft skills development which are more important than academic performances (Acuff, Soltis, Dennhardt, Borsari, Martens and Murphy, 2017). The soft skills are including social skills, ethics, values; communication, leadership and teamwork, problem-solving skills and scientific thinking; information management and life-long learning; entrepreneurship and management.

The focus on those soft skills are key initiatives outlined in Malaysia Education Blueprint (Higher Education) (2012-2025) which was launched back in April 2015. The undergraduates are required to invest time and effort in activities and initiatives both inside and outside the classroom. Assessment of academic competence, character development and non-academic competencies development are conducted in every semester throughout their studies. Hence, the undergraduates are encouraged to develop a more balance characters and roles between academic and non-academic requirements. In turn, they will experience less stress level among themselves (Abdullah, 2015). In addition, undergraduate differences with different goal expectations towards academic performance achievement instead of following standardized expectation from social norms and family expectation. Therefore, the academic performance is less likely to be considered as a stressor among undergraduates (Ganguly et al., 2017).

The present findings indicated that there was a significant negative relationship between self-esteem and perceived stress, $\mathrm{H}_{2}$ was supported. The finding was consistent with previous studies (Srivastava and Kiran, 2015; Lee et al., 2013) that individuals with lower self-esteem always experience higher level of stress. As highlighted in the model of stress (Robbins, \& Judge, 2013), self-esteem is viewed as an individual-related factor which will bring impacts to one's experienced stress. Generally, self-esteem development is always associated with childhood upbringing background, parenting styles, socio economics status and family influences (Firouzkouhi, Validad, Rakhshani and Assareh, 2017; Ju and Lee, 2010). Empirical findings explained that an individual with low self-esteem due to low socio economics status (Veselska, Geckova, Reijneveld and van Dijk, 2011) and high permissive parenting styles (Yousaf, 2015), consequently, there is higher level of perceived stress faced by the individual.

In a similar vein, the present study found that there was significant negative relationship between perceived social support and perceived stress, $\mathrm{H}_{3}$ was supported. The findings were in line with past studies by Wainer (2013) and Çivitçi and Durmuş (2015). The individual who have high perceived social support is expected to have lower perceived stress. The social support from peers and family members could assist them in managing tress level in a more efficient manner and be confident to face the challenges in future (Sultan and Rashid, 2015; Malinauskas, 2010). The findings support both (i) Cognitive Appraisal and Stress model that individual with good and consistent social supports are more likely to be competent to deal with the stressful situation with scared resources (Lazarus, 2000); (ii) Carl Rogers' Person-Centered theory depicted that individual could be stressful when he or she has a real self of low perceived social support (i.e., peer rejection) as compared with his or her ideal self which indicated that high perceived level of social (Telles et al., 2014; Ciccarelli and White, 2015; Fernández-González et al., 2015). 


\section{Implications}

The current findings aim to provide an in-depth understanding on Malaysia undergraduates' wellbeing conditions, especially their stress level which is important in assisting them holistically succeed in $21^{\text {st }}$ century as outlined in Malaysia Education Blueprint 2013-2025 (Ministry of Education Malaysia, 2013). The tertiary programs syllabus or co-curriculums should be reviewed periodically by imbued with right values and ethics, enabling undergraduates to manage their stress level and make the right choices for themselves, families and the country with a view towards enduring and overcoming life's inevitable challenges (Ministry of Education Malaysia, 2013). The Malaysian higher education institutions could employ Public Health Model (Kohler and Munz, 2006) and Yerkes-Dodson Law (Martin, 2015) in order to implement relevant stress management programs to all the undergraduates. The stress management interventions should be customized based on the undergraduates' attitude, personalities and social culture (Kohler and Munz, 2016). For example, undergraduates' personal development and coaching programs to be conducted in order to improve their social interaction competencies and social support in order to reduce their stress level (Malinauskas, 2010).

In addition, mentoring system could be practiced to assist undergraduates in their varsity life. Undergraduates may view mentoring program as part of learning and self-development strategies. An experienced peer (i.e., mentor) applies guided learning to assist a less experienced peer in developing appropriate stress management skills. A mentor can provide coaching, friendship, and role modeling to the juniors (i.e., less experienced peer) particularly in handling their stress. Universities can implement effective mentoring programs, including counseling and coaching, and emotional support to all undergraduates. The counselling programs are designed in order to allow mentors and juniors to develop mutually supportive bonds. Such social bonds is important in assisting juniors to manage their study stress with appropriate stress management solutions.

In addition, the caretakers/parents should in touch and cooperate with higher education institutions in order to understand the undergraduates' self-esteem, mental health, socialization behaviours, as well as their total wellbeing (Glover and Friedmann, 2015). A good supportive relationship is vital to improve mental or physical health of undergraduates. Caretakers could practice family therapy in order to assist the undergraduates who experience high level of stress. Family therapy engage all the family members to share their life experiences, render moral supports and empathy towards one another in order to go through the hardships and challenges of life (Franklin, 2013).

Regarding to personal intervention, undergraduates should always be mindful and aware of negative thoughts which leads to self-fulfilling prophecy (Ciccarelli and White, 2015). Undergraduates must develop appropriate values in pursuing the set objectives, put forth the required effort, and believe unquestioningly in their ability to reach those goals. The coaches/parents/academicians should communicate their viewpoints to undergraduates regularly. They should discuss with the undergraduates and determine how much efforts that they are willing to exert to handle setbacks, and offers suggestions to overcome the problem. 
Besides, undergraduates should also be forgiveness and openness to past or future experiences so that unpleasant incidents can be managed properly (Ciccarelli and White, 2015). Particularly one could increase his or her self-esteem via high level of forgiveness and high openness in order to reduce stress level (Soudi, Duggi, Bhandari and Kamble, 2015).

\section{Limitations and Future Suggestions}

The study limitations and suggestions for future research are provided. First, the sample of this study is undergraduates from local and private universities. The generalization of the study findings may be limited. Further studies can be conducted by including different industries (e.g., tourism, health care and other service sector) for the purpose of improving generalizability. Second, this study did not examine demographic variables as factors to affect perceived stress among undergraduate. It is recommended to consider some demographics variables such as gender and years of study in order to obtain more comprehensive results on the predictors of the perceived stress. The mediating and moderating effects of those variables to be considered as well. Furthermore, qualitative-based research could be considered in future study where it has the advantages of real-time and adaptive.

\section{Conclusion}

The findings indicated that self-esteem and perceived social support were negatively associated to undergraduates perceived. However, there is no significant relationship between academic performance and perceived stress. Future studies should look into qualitative or experimental studies, more potential variables and representativeness of recruited participants.

\section{Acknowledgement and Sponsoring Information}

The authors received financial support for the research, authorship, and/or publication from HELP University, Malaysia of this article.

\section{References}

Abdullah, D. (2015). Ambitious higher education reform in Malaysia: ICGPA, graduate employment and the student development agenda. The Observatory on Borderless Higher Education, 1-4. Retrieved from http://18\%20iCGPA\%20ML\%20FINAL\%2023Sep15.pdf

Acuff, S. F., Soltis, K. E., Dennhardt, A. A., Borsari, B., Martens, M. P., \& Murphy, J. G. (2017). Future so bright? Delay discounting and consideration of the future consequences predict academic performance among college drinkers. Experimental and Clinical Psychopharmacology, 25(5), 412-421. https://doi.org/10.1037/pha0000143

Adamo, S. A. (2012). Review: The effects of the stress response on immune function in invertebrates: An evolutionary perspective on an ancient connection. Special Issue: The Neuroendocrine-Immune Axis in Health and Disease, 62(3), 324-330. https://doi.org/10.1016/j.yhbeh.2012.02.012

Adisa, R., Olajide, O. O., \& Fakeye, T. O. (2017). Social support, treatment adherence and outcome among hypertensive and type 2 diabetes patients in ambulatory care settings in 
southwestern Nigeria. Ghana Medical Journal, 51(2), 64-77.

Ali, A. B., \& Mahmod, S. (2018). Level of soft skill in the implementation of work-based learning among community students. https://doi.org/10.1051/matecconf/201815005041

Anuradha, R., Dutta, R., Raja, J. D., Sivaprakasam, P., \& Patil, A. B. (2017). Stress and stressors among medical undergraduate students: A cross-sectional study in a private medical college in Tamil Nadu. Indian Journal of Community Medicine, 42(4), 222-225. https://doi.org/10.4103/ijcm.IJCM_287_16

Brill, R. T., Gilfoil, D. M., \& Doll, K. (2014). Exploring predictability of instructor ratings using a quantitative tool for evaluating soft skills among MBA students. American Journal of Business Education, 7(3), 175-182. https://doi.org/10.19030/ajbe.v7i3.8627

Brown, K., Anderson-Johnson, P., \& McPherson, A. N. (2016). Midwifery education in practice: Academic-related stress among graduate students in nursing in a Jamaican school of nursing. Nurse Education in Practice, 20, 117-124. https://doi.org/10.1016/j.nepr.2016.08.004

Ciccarelli, S. K., \& White, J. N. (2015). Psychology. United Stated: Pearson Education.

Çivitçi, A., \& Durmuş, A. (2015). The moderating role of positive and negative affect on the relationship between perceived social support and stress in college students. Educational Sciences in Theory and Practice, 15(3), 565-573. https://doi.org/10.12738/estp.2015.3.2553

Cohen, S. (1994). Perceived Stress Scale. Retrieved from http://www.mindgarden.com/documents/PerceivedStressScale.pdf

Fernández-González, L., González-Hernández, A., \& Trianes-Torres, M. V. (2015). Relationships between academic stress, social support, optimism-pessimism and self-esteem in college students. Electronic Journal of Research in Educational Psychology, 13(1), 111-130. https://doi.org/10.14204/ejrep.35.14053

Ferradás Canedo, M. D. M., Freire Rodríguez, C., Regueiro Fernández, B., \& Valle Arias, A. (2018). Defensive pessimism, self-esteem and achievement goals: A person-centered approach. Psicothema, 30(1), 53-58.

Firouzkouhi, M. M., Validad, A., Rakhshani, T., \& Assareh, M. (2017). Child self-esteem and different parenting styles of mothers: A cross-sectional study. Archives of Psychiatry and Psychotherapy, 19(1), 37-42. https://doi.org/10.12740/APP/68160

Franklin, N. G. (2013). Effects of academic stress and perceived social support on the psychological wellbeing of adolescents in Ghana. Open Journal of Medical Psychology, 2(4), 143-150. https://doi.org/10.4236/ojmp.2013.24022

Furr, S. R., Westefeld, J. S., McConnell, G. N., \& Jenkins, J. M. (2001). Suicide and depression among college students: A decade later. Professional Psychology: Research and Practice, 32(1), 97-100. https://doi.org/10.1037/0735-7028.32.1.97 
Ganguly, S., Kulkarni, M., \& Gupta, M. (2017). Predictors of academic performance among Indian students. Social Psychology of Education, 20(1), 139-157. https://doi.org/10.1007/s11218-016-9345-y

Glover, J., \& Friedmann, H. L. (2015). Transcultural competence: Navigating cultural differences in the global community. Washington, DC: American Psychological Association. https://doi.org/10.1037/14596-000

Guerra-Martín, M. D., Lima-Serrano, M., \& Lima-Rodríguez, J. S. (2017). Effectiveness of tutoring to improve academic performance in nursing students at the University of Seville. Journal of New Approaches in Educational Research, 6(2), 93-102. https://doi.org/10.7821/naer.2017.7.201

Hair, J. F., Hult, G. T. M., Ringle, C. M., \& Sarstedt, M. (2017). A primer on Partial Least Squares Structural Equation modelling ( ${ }^{\text {nd }}$ ed.). Thousand Oaks: Sage.

Hasan, S., \& Fatima, M. (2017). Factors affecting the academic performance of university students residing in student housing facility. Khazar Journal of Humanities \& Social Sciences, 21(1), 83-100.

Jenaabadi, H., Nastiezaie, N., \& Safarzaie, H. (2017). The relationship of academic burnout and academic stress with academic self-efficacy among graduate students. New Educational Review, 49(3), 65-76. doi: 10.15804/tner.2017.49.3.05

Ju, S., \& Lee, Y. (2010). Experiences of family maltreatment by Korean children in Korean National Protective Services. Child Abuse \& Neglect, 34(1), 18-27. https://doi.org/10.1016/j.chiabu.2009.09.009

Ju, S., \& Lee, Y. (2018). Developmental trajectories and longitudinal mediation effects of self-esteem, peer attachment, child maltreatment and depression on early adolescents. Child Abuse \& Neglect, 76, 353-363. https://doi.org/10.1016/j.chiabu.2017.11.015

Kohler, J. M., \& Munz, D. C. (2006). Combining individual and organization stress interventions: An organizational development approach. Counselling Psychology Journal: Practice and Research, 58(1), 1-12.

Lazarus, R. S. (2000). Toward better research on stress and coping. American Psychologist, 55(6), 665-673. https://doi.org/10.1037/0003-066X.55.6.665

Lee, J. S., Joo, E. J., \& Choi, K. S. (2013). Perceived stress and self-esteem mediate the effects of work-related stress on depression. Stress and Health: Journal of the International Society for the Investigation of Stress, 29(1), 75-81. https://doi.org/10.1002/smi.2428

Malinauskas, R. (2010). The Associations among social support, stress, and life satisfaction as perceived by injured college athletes. Social Bahvior \& Personality: An International Journal, 38(6), 741-752. https://doi.org/10.2224/sbp.2010.38.6.741

Martin, C. (2015). From law to folklore: Work stress and the Yerkes-Dodson Law. Journal of Managerial Psychology, 30(6), 741-752. https://doi.org/10.1108/JMP-03-2013-0085 


\section{$\triangle$ Macrothink}

International Journal of Human Resource Studies

ISSN 2162-3058

2018, Vol. 8, No. 4

Meszaros, K., \& De Wals, S. (2011). Handbook on psychology of self-esteem. Hauppauge, NY: Nova Science Publishers.

Mihăilescu, A. I., Diaconescu, L. V., Donisan, T., \& Ciobanu, A. M. (2016). The influence of emotional distress on the academic performance in undergraduate medical students. Romanian Journal of Child \& Adolescent Psychiatrist, 4(1/2), 27-40.

Mimura, C., Murrells, T, \& Griffiths, P. (2009). The association between stress, self-esteem and childhood acceptance in nursing and pharmacy students: A comparative cross-cultural analysis. Stress \& Health: Journal of the International Society for the Investigation of Stress, 25(3), 209-220. https://doi.org/10.1002/smi.1240

Ministry of Education Malaysia. (2013). Malaysia education blueprint 2013-2015 (Preschool to post-secondary education). Retrieved from https://www.moe.gov.my/images/dasar-kpm/articlefile_file_003108.pdf

Negga, F., Applewhite, S., \& Livingston, I. (2007). African American college students and stress: School racial composition, self-esteem and social support. College Student Journal, 41(4), 823-830.

Opoku-Acheampong, A., Kretchy, I. A., Acheampong, F., Afrane, B. A., Ashong, S., Tamakloe, B., \& Nyarko, A. K. (2017). Perceived stress and quality of life of pharmacy students in University of Ghana. BMC Research Notes, 10, 1-7. https://doi.org/10.1186/s13104-017-2439-6

Prime Minister's Department. (2011). Economic Transformation Programme: Annual report 2011. Putrajaya: Performance Management and Delivery Unit.

Robbins, S. P. \& Judge, T. A. (2013). Organizational behaviour $\left(15^{\text {th }}\right.$ ed.). New York, NYC: Pearson Education.

Soudi, S. P., Duggi, D., Bhandari, S., \& Kamble, S. V. (2015). Self-esteem and forgiveness in PG students. Indian Journal of Positive Psychology, 6(1), 114-116.

Srivastava, P., \& Kiran, M. (2015). The relationship between perceived stress, self-esteem, way of coping and problem solving ability among school going adolescents. Journal of Psychosocial Research, 10(2), 199-209.

Sultan, S., \& Rashid, S. (2015). Perceived social support mediating the relationship between perceived stress and job satisfaction. Journal on Educational Psychology, 8(3), 36-42. https://doi.org/10.26634/jpsy.8.3.3103

Swacha, G., Botta-Dukát, Z., Kącki, Z., Pruchniewicz, D., \& Żołnierz, L. (2017). A performance comparison of sampling methods in the assessment of species composition patterns and environment-vegetation relationships in species-rich grasslands. Acta Societatis Botanicorum Poloniae, 86(4), 1-15. https://doi.org/10.5586/asbp.3561

Tangaraju, K., Ho, C. S., Tan, L. K., Tan, S. Y., \& Tan, W. M. (2013). Analysis of factors influence the academic performance of undergraduates in Kampar (Degree's thesis). 
Retrieved from http://eprints.utar.edu.my/1016/1/AC-2013-0904962-1.pdf

Telles, T. C. B., Boris, G. D. J. B, \& Moreira, V. (2014). The actualizing tendency concept in contemporaneous humanistical psychotherapists' clinical practice. Journal of the Gestalt Approach, 20(1), 13-20.

The Star Online. (2013). College student falls to her death. Retrieved from http://www.thestar.com.my/news/nation/2013/08/29/college-student-falls-to-her-death-girl-be lieved-to-be-suffering-from-exam-stress/

Veselska, Z., Geckova, A. M., Reijneveld, S. A., \& van Dijk, J. P. (2011). Socio-economic status and physical activity among adolescents: The mediating role of self-esteem. Science in Health Ageing \& Healthcare, 125(11), 763-768. https://doi.org/10.1016/j.puhe.2011.09.007

Wainer, J. S. (2013). Perceived stress, perceived social support, depression and food consumption frequency in college students. Retrieved from http://ezproxy.help.edu.my:2052/eds/detail/detail?vid=0\&sid=d3221993-5749-4e28-af18-fb9 02b8575a7\%40sessionmgr4009\&bdata=JnNpdGU9ZWRzLWxpdmU\%3d\#AN=edsbas.ftcite seerx.oai.CiteSeerX.psu.10.1.1.359.4467\&db=edsbas

World Health Organization. (2017). Suicide rates, crude. Retrieved from http://apps.who.int/gho/data/node.main.MHSUICIDE

Yan, Y. W., Lin, R. M., \& Su, Y. K. (2018). The relationship between adolescent academic stress and sleep quality: A multiple mediation model. Social Behavior \& Personality: An International Journal, 46(1), 63-78. https://doi.org/10.2224/sbp.6530

Yousaf, S. (2015). The relation between self-esteem, parenting style and social anxiety in girls. Journal of Education and Practice, 6(1), 140-142.

Yunus, A. (2018). Lam Thye offers recommendations for improving country's healthcare services. $\quad$ Retrieved from https://www.nst.com.my/news/nation/2018/06/376136/lam-thye-offers-recommendations-imp roving-countrys-healthcare-services

Yurdakul, M. (2018). Perceived social support in pregnant adolescents in Mersin area in Turkey. Pakistan Journal of Medical Sciences, 34(1), 1-6. https://doi.org/10.12669/pjms.341.14221

Zhang, J., \& Li, Z. (2013). The association between depression and suicide when hopelessness is controlled for. Comprehensive Psychiatry, 54(7), 790-796. https://doi.org/10.1016/j.comppsych.2013.03.004

\section{Copyright Disclaimer}

Copyright for this article is retained by the author(s), with first publication rights granted to the journal.

This is an open-access article distributed under the terms and conditions of the Creative Commons Attribution license (http://creativecommons.org/licenses/by/4.0/). 